\title{
Les tables de canons : la Bible de Saint-Bénigne. Notes pour un projet de recherches en cours
}

\section{Maria Cristina Pereira}

\section{(2) OpenEdition \\ 1 Journals}

\section{Édition électronique}

URL : https://journals.openedition.org/cem/7172

DOI : $10.4000 /$ cem. 7172

ISSN : 1954-3093

Éditeur

Centre d'études médiévales Saint-Germain d'Auxerre

\section{Édition imprimée}

Date de publication : 15 août 2008

ISSN : 1623-5770

\section{Référence électronique}

Maria Cristina Pereira, «Les tables de canons : la Bible de Saint-Bénigne.

Notes pour un projet de recherches en cours ", Bulletin du centre d'études médiévales d'Auxerre

BUCEMA [En ligne], 12 | 2008, mis en ligne le 09 avril 2009, consulté le 22 septembre 2022. URL

http://journals.openedition.org/cem/7172 ; DOI : https://doi.org/10.4000/cem.7172

Ce document a été généré automatiquement le 22 septembre 2022.

\section{c) (i) (8)(2)}

Creative Commons - Attribution - Pas d'Utilisation Commerciale - Partage dans les Mêmes Conditions 4.0 International - CC BY-NC-SA 4.0

https://creativecommons.org/licenses/by-nc-sa/4.0/ 


\title{
Les tables de canons : la Bible de Saint-Bénigne. Notes pour un projet de recherches en cours
}

\author{
Maria Cristina Pereira
}

1 Les tables des canons - ou, en d'autres termes, l'encadrement ornemental des canons eusébiens - n'ont jamais été un thème privilégié par les historiens de l'art, si l'on se réfère au nombre réduit de travaux à leur sujet. Cependant, elles nous semblent un objet d'étude fort intéressant, surtout quand on s'intéresse au travail ornemental ou aux rythmes des images.

2 Le premier dossier examiné dans la recherche que nous venons de commencer sur les Tables des canons est celui de la Bible de Saint-Bénigne de Dijon (DIJon, Bibliothèque municipale, ms. 2), datée du deuxième quart du XII ${ }^{e}$ siècle (Y. Zaluska) ${ }^{1}$. Plus connue pour ses nombreuses initiales ornées, cette bible de grande dimension (502 folios de $518 \times 360 \mathrm{~mm}$ ) présente une série de sept tables (fol. 402v-405v) - une huitième ayant été arrachée avant la numérotation moderne des feuillets - d'une riche et complexe ornementation, avec des motifs architecturaux, végétaux et animaux, en plus de personnages humains et hybrides, assez souvent affrontés.

3 Leur étude permet d'établir des comparaisons, de distinguer les similarités et les variations, d'approcher les rythmes des images. On ne voit jamais ni répétition ni régularité dans l'emploi des motifs ornementaux, lesquels ne sont pas non plus hasardeux. Au contraire, ils sont très recherchés, faisant preuve d'un travail soigné de création de symétries et d'asymétries qui sont propres à chaque table.

Dans la Bible de Saint-Bénigne, il est question, avant tout, d'une puissante et remarquable présentation ornementale des canons - ou de l'ornemental mis au travail dans ses feuillets. On pourrait dire que c'est cet encadrement décoratif qui ordonne, structure et aussi apporte une série de significations aux listes de chiffres romains et même à l'ensemble des sept feuillets, tout en les ornant. Ce pouvoir, dont se trouvent investies 
les images, est aussi d'ordre monumental : parmi ses multiples fonctions, l'ornemental possède également celle de rapprocher la structure des tables de celle d'une église, avec ses colonnes, ses chapiteaux, ses arcades, ses tympans et ses tours. Plus spécifiquement, on pourrait établir le parallèle entre cette opération de construction d'un cadre monumental et architecturé, pour les tables des canons, et l'entreprise menée par Guillaume de Volpiano, abbé de Saint-Bénigne de Dijon, quand il fit construire la grande coupole afin d'y abriter les reliques du saint patron, leur fournissant alors une sorte de " sur-encadrement », projeté vers le haut.

5 Les tables de canons mettent ainsi en valeur la construction intellectuelle qu'est la concordance des Évangiles, en la rapprochant du travail de construction et de maçonnerie. Toutefois, en même temps, ce "sur-encadrement» des tables ne fonctionne pas que dans le rapprochement des formes, mais aussi dans la différence : les thèmes iconographiques les plus fréquents sont des combats. La discordance ne fait ainsi que mieux ressortir la concordance.

6 Ce sont ces voies de recherche que nous nous proposons de poursuivre afin de mieux comprendre l'intérêt du manuscrit, du double point de vue iconographique et historique, en accordant toute leur place aux notions de " décor » et d'« image », selon la perspective d'une étude globale.

\section{NOTES}

1. Notre recherche a pu bénéficier d'un séjour de trois mois à Dijon en tant que chercheur associée du CNRS, au sein de l'UMR 5594 ARTeHIS, à l'Université de Bourgogne, dirigée par M. Daniel Russo, que nous remercions vivement. C'est, du reste, après en avoir discuté avec lui que nous avons commencé cette étude sur le manuscrit 2 de la Bibliothèque municipale de Dijon, dit Bible de Saint-Bénigne.

\section{INDEX}

Index géographique : France/Dijon

Mots-clés : Bible, Saint-Bénigne de Dijon, Canon de la messe

\section{AUTEUR}

\section{MARIA CRISTINA PEREIRA}

Universidade Federal do Espírito Santo, Brésil 